\title{
Italo Calvino y su lectura de Borges: historia de una canonización.
}

Enrique Santos Unamuno

Universidad de Milán. Italia

1.

El binomio crítico-literario Calvino-Borges, que hizo su tímida aparición a principios de los años 60 , se convirtió en mención obligada en la década sucesiva y, tras veinte años de fortuna, ha llegado hasta nosotros como dato incontrovertible referido a la vulgata de ambos escritores, una certidumbre bien visible en el Congreso celebrado en la ciudad de Poitiers en 1994 en torno a las relaciones entre el italiano y el argentino, cuyo título rezaba muy significativamente "Borges, Calvino, la littérature" (Sicard-Moreno eds., 1996). No obstante, al igual que todas las ideas recibidas, semejante combinación corre el riesgo de convertirse en estéril etiqueta, cuando no en socorrido expediente simplificador, peligros conjurados por algunas contribuciones críticas. De entre ellas nos interesan en especial las referidas a la lectura de la obra borgeana llevada a cabo por Italo Calvino, tema central de las siguientes reflexiones.

Roberto Paoli trazaba en 1993 una descripción de la interpretación dada por Calvino de la obra borgeana, estableciendo los años 60 como el término a partir del cual el escritor italiano empieza a citar al argentino en sus intervenciones teóricas y a asimilarlo en su obra narrativa. Según Paoli, dichas menciones y dicha influencia se irán acentuando a lo largo de los años, hasta llegar a su culmen en el discurso pronunciado en honor a Borges en octubre de 1984 (con motivo del homenaje tributado al escritor argentino por el Presidente de la República Italiana, Sandro Pertini) ${ }^{1}$ y en Lezioni americane. Ambos textos son la base de la argumentación de Paoli en lo que respecta a la lectura teórica (en términos de poética) de la obra borgeana por parte de Calvino, una argumentación reelaborada recientemente (sin variaciones sustanciales) en "Borges in Calvino", uno de los capítulos del trabajo dedicado por el estudioso italiano a las relaciones de ida y vuelta entre Borges y la cultura italiana (Paoli, 1993: págs. 152-157; 1997: págs. 25-40)².

Parte también de Lezioni americane Saúl Yurkievich quien, tras haber examinado con agudeza algunos rasgos comunes a uno y otro escritor, llama la atención acerca de la verdadera naturaleza de la operación calviniana y afirma que, aclarando las razones poéticas de Borges, el italiano expresa indirectamente las suyas (Yurkievich, 1996: pág. 33).

Giuseppe Nava, por su parte, distingue diferentes fases de asimilación presentes en el recorrido literario del italiano, identificando en la década de los 60 el momento de mayor simbiosis entre ambos autores, con una asimilación de temas y 
módulos de Borges por parte de Calvino, bajo el signo de una narrativa de inspiración lógico-científica. Simbiosis que decrecería, según Nava, en la producción calviniana de los años 70, en la que predominarían más los elementos estructurales y metanarrativos que los de tipo lógico característicos de Borges. En este itinerario, el discurso del 84 aparecería como un ejercicio de la memoria, una especie de recapitulación en un momento en el que el ejemplo del argentino había dejado de tener "una carica propulsiva" (Nava, 1996: págs. 68-70).

También Martin L. Mclaughlin se remite al análisis calviniano del 84, identificando cuatro puntos de contacto entre ambos escritores (los mismos que señala Calvino como definidores del argentino). Avalando la difusa opinión que ve una cesura brusca en la obra calviniana a partir del año 62/63, Mclaughlin circunscribe la influencia de Borges en el italiano sólo a partir de dicha ruptura, señalando que probablemente "Borges è causa e sintomo di questo cambiamento di gusto" (Mclaughlin, 1996: pág 91). Por otra parte, se identifica en los años 70 el momento en el que el modelo borgeano da los frutos más maduros en la obra de Calvino, precisamente a través del recurso a fórmulas metanarrativas (opinión diametralmente opuesta a la ya citada de Giuseppe Nava) ${ }^{3}$. Mclaughlin concluye afirmando el carácter discontinuo de la relación de Calvino con la obra de Borges, "non una fulminea conversione sulla strada di Damasco" (ibid, págs. 102-103) sino más bien un proceso gradual coronado, en los años inmediatamente anteriores a la muerte de Calvino, por una asunción en bloque de la poética borgeana cifrada en las formas breves (ibid.).

Más prudente se muestra Pier Luigi Crovetto quien, en un reciente congreso dedicado al escritor italiano, abogaba por una mayor conciencia crítica a la hora de deslindar los diferentes aspectos que acercan y separan a Borges y Calvino y afirmaba que, leyendo la bibliografía específica, se tiene

"l'impressione che le differenze tendano a stemperarsi in una sorta di disegno troppo armonico e tondeggiante di corrispondenze e di reciproci apprezzamenti" (Crovetto, 1996) ${ }^{4}$.

Una intuición sin duda muy acertada referida a un fenómeno cuyas causas, a nuestro parecer, han de buscarse en la exclusiva atención crítica recibida por los dos últimos textos en los que Calvino dio una visión de conjunto de la poética borgeana: es decir, el discurso del 84 y las conferencias que constituyen Lezioni americane. En otras palabras, el análisis crítico resultante de tal operación corre el riesgo de dar la preferencia a la imagen que el propio Calvino, una vez llegado a la madurez artística, se construyó de su lectura de Borges, movido sobre todo por su afán de perpetuar la propia memoria en virtud de su inclusión en el panteón de los clásicos del siglo XX.

No olvidemos, a este respecto, la ingente labor del Calvino editor, redactor de prefacios e introducciones, incansable sistematizador de corrientes y humores literarios. En última instancia, el autor italiano ajusta siempre cuentas consigo mismo, erigiéndose en "teorizzatore e editore di se stesso" (Ferretti, 1998) incluso cuando se refiere a obras ajenas, utilizadas como pretexto

"per ritrovare i termini, le prospettive, i progetti della propria ricerca, della propria scrittura"

(Patrizi, 1993: pág. 126).

Desde este punto de vista, libros de prosa ensayística como Una pietra sopra (1980), el póstumo e inconcluso Lezioni americane (1988) y, en menor medida, Collezione di sabbia (1984) (a los que deberían añadirse sus numerosas intervenciones críticas, en buena parte recogidas en la opera omnia mondadoriana), se nos presentan como reelaboraciones a posteriori de la propia evolución poética, consecuencias de un consciente trabajo de selección, eliminación y disposición de elementos destinados a crear una imagen determinada de sí mismo y de su recorrido 
literario, una autocanonización o "autopromoción" (Benedetti, 1998: 24) cuyas implicaciones el crítico ha de tener siempre bien presentes, siguiendo en ello la recomendación de uno de los más finos intérpretes calvinianos: "non fidarsi delle sue sistemazioni 'a posteriori’” (Bertone, 1994: pág. 92).

A la luz de esta prudente máxima crítica, la repetida insistencia de Calvino acerca de su carácter de escritor "menor" ${ }^{5}$, ha de ser tamizada analizando y cotejando sus escritos teóricos a lo largo de los años 50-70, una operación que nos permitirá "desenmascarar" la falsa modestia del escritor italiano y captar la filigrana de lo que fue un (legítimo) proyecto constante por su parte: pasar a engrosar las filas del canon literario occidental, junto a los grandes escritores de todas las épocas. Para poder hacerlo, Calvino precisó de maestros ya consagrados, guías de viaje, interactuando con ellos en un campo de atracción y repulsión cambiante, hasta llegar a los definitivos años 80-85, en los que asistimos a dos fenómenos fundamentales: si, por una parte, la rosa de los nombres se va haciendo cada vez más estrecha, por la otra, la relación maestro-alumno va dejando paso de forma casi imperceptible a una camaradería literaria entre pares basada más en afinidades que en influencias. La lectura de la obra borgeana llevada a cabo por Calvino refleja a la perfección todo lo dicho y constituye uno de los cauces fundamentales utilizados por el italiano en lo que denominaremos su labor de "canonización", recurriendo a un término especialmente debatido entre los estudiosos en los últimos tiempos.

2.

El origen bíblico de la noción de "canon" se halla relacionado con la gestión del poder. A través de la canonización se suscribe la autoridad de un texto respecto a otros, así como en lo tocante al presente y el futuro en el que reinará como texto capaz de vincular una comunidad de personas ${ }^{6}$. Sin negar los aspectos políticos y sociales de la práctica canonizadora, puestos de relieve en los últimos años por corrientes críticas como el feminismo o el multiculturalismo, es preciso subrayar que los cánones literarios no poseen un carácter tan rígido como dichas corrientes tienden a postular, ya que se transforman más deprisa de lo que parece y están sujetos a cierta precariedad y transitoriedad directamente ligadas a las modas académicas o editoriales del momento (Landow, 1992: pág. 191). Harold Bloom, en abierta polémica con los nuevos derroteros de lo políticamente correcto (el crítico estadounidense habla a este respecto de "Escuela del Resentimiento"), pone el dedo en la llaga cuando afirma el carácter elitista y a la vez abierto de cánones y contracánones, aplicando su teoría de la "angustia de la influencia” a la formación del canon literario. Según Bloom, toda gran obra literaria lee erróneamente y malinterpreta uno o más textos preexistentes, dando cuerpo a un proceso de naturaleza agonística, una lucha entre el genio anterior y el aspirante en la que el premio es la inclusión en el canon y la supervivencia literaria ${ }^{7}$. De este modo, la formación del canon no sería tanto responsabilidad de los críticos, los académicos o los políticos, sino que estaría directamente ligada a los escritores, quienes ac- 
túan "tendiendo puentes entre poderosos precursores y poderosos sucesores" (Bloom, 1994: pág. 530).

A partir de semejantes consideraciones, en las próximas páginas trataremos de rastrear la lectura que Italo Calvino llevó a cabo de la obra de Borges, enlazándola con sus propias vicisitudes poéticas. Un itinerario caracterizado, en nuestra opinión, por una progresiva ubicación del argentino en el centro del panteón literario de nuestro tiempo, acompañada a su vez por un intento de autocanonización literaria por parte de Calvino. No olvidemos, en este orden de cosas, la importancia concedida por el escritor italiano durante toda su vida a la lectura y difusión de los clásicos, así como a la sistematización clara y precisa de las obras literarias, bien visible, por ejemplo, en su faceta de editor y en su labor como antólogo para la escuela media y superior ${ }^{8}$.

3.

Será el mismo Calvino quien nos ayude a delimitar con cierta precisión el momento en el que emprenderá la lectura de la obra del argentino. En una entrevista concedida un año antes de su desaparición, el escritor italiano afirma:

"Borges [...] era stato appena pubblicato in Francia. Mi ricordo un numero di 'Temps Modernes' in cui c'erano dei racconti di Borges e fu il poeta Sergio Solmi il primo a dire che c'era in giro uno scrittore straordinario che valeva la pena di leggere. Io allora lavoravo presso Einaudi e lo lessi in francese, perché non conoscevo ancora lo spagnolo. Franco Lucentini fu il primo traduttore di Borges" (Calvino, 1984). Si tenemos en cuenta que la primera traducción francesa en volumen de los relatos de Borges publicada en Francia fue Fictions, volumen No1 de la colección "La Croix du Sud", aparecido en 1951 por cuenta de la editorial Gallimard, seguido en el 53 por L'aleph (Genot, 1969: pág. 160; Vian, 1980: pág. 192; Bernès, 1993: págs. XIV-XVI), y que la traducción italiana de Lucentini vio la luz en 1955, no será arriesgado concluir que el primer contacto de Calvino con la obra de Borges se verificó probablemente entre 1951 y $1954^{\circ}$, años de gran importancia en la gestación de la poética calviniana, si bien el autor italiano procederá con posterioridad a eliminar cualquier alusión a tan trabajosos años, como puede deducirse fácilmente de su libro de ensayos Una pietra sopra (1980), autobiografía ideal del Calvino maduro cuyo primer texto, el famoso "Il midollo del leone", salta de forma muy significativa hasta el año 1955, cancelando de un plumazo la década 1945-1955, caracterizada en su caso por las lucubraciones teóricas relativas a la función de la literatura y del escritor en el seno de la sociedad y su relación con el resto de las actividades humanas y por el problema del género, tanto desde un punto de vista formal (novela $v s$ relato) como modal (realismo $v s$ literatura fantástica).

Giorgio Bertone ha estudiado con detenimiento este período de la producción del escritor italiano, viendo en los narradores rusos y franceses del siglo XIX los 
modelos clásicos del joven Calvino, fascinado asimismo por la lección literaria y humana de Cesare Pavese y, a través de éste, por la literatura narrativa norteamericana (Bertone, 1994: págs. 3-118). Buen ejemplo de ello es su relación con Ernest Hemingway, considerado por el Calvino de estos años un modelo de narrador práctico, de "escritor artesano" ${ }^{10}$, en el que literatura y vida se funden indisolublemente a través de la manualidad y la experiencia vivida. El objetivo del intelectual nuevo, para el joven Calvino, era la construcción de una cultura proletaria que no se basara en un rechazo ahistórico y romántico de la civilización industrial (en la línea del hermetismo y el decadentismo simbolistas y psicologistas anteriores a la $2^{\text {a }}$ guerra mundial), pero que a su vez no se plegara a los dictados de un realismo socialista reductivo y estéril ${ }^{11}$. En este proyecto, el escritor se erige en Homero tecnológico capaz de fundir los valores universales de la literatura con los aspectos históricos de la sociedad por medio de la prosa narrativa y, concretamente, novelística.

En efecto, muchas de las cartas de ese periodo, incluidas en esa muestra del epistolario editorial de Calvino que es I libri degli altri. Lettere 1947-1981, pueden ser leídas transversalmente como testimonios de las enormes dificultades encontradas por el escritor italiano a la hora de llevar a la práctica su proyecto poético. Una dificultad que alcanza su culmen en 1954 (en el período, no lo olvidemos, de sus primeras lecturas borgeanas), año en el que el escritor italiano abandonará definitivamente ese proyecto que con tanta pertinacia había perseguido en los años anteriores: la elaboración de una epopeya realista que representara la situación del proletariado en el seno de la nueva civilización industrial y urbana. Es significativo a este respecto el ensayo "Hemingway e noi", publicado en Il Contemporaneo en noviembre del 54, una especie de balance conclusivo de la propia poética en los años 45-55, con la consiguiente inversión del juicio reservado al narrador estadounidense, del que se denuncian vicios y límites estilísticos, a la vez que se subraya la distancia respecto a su concepción literaria. A partir de este momento, se irá agudizando en Calvino la conciencia de la crisis del mundo de la Naturaleza y de la Historia, como se puede observar en ensayos tan comentados como "Il midollo del leone" (1955) o "Il mare dell'oggettività" (escrito en 1959 y publicado en 1960). Desde un punto de vista formal, asistimos de forma paralela al abandono definitivo del género novelístico ${ }^{12}$, mientras en el aspecto temático pasa a primer plano el sentimiento de la complejidad y del carácter laberíntico de lo real. ¿Hasta qué punto la lectura de Borges puede haber influido en esta idea de una literatura racional del laberinto que intenta superponerse al laberinto caótico del mundo?

Un atisbo de respuesta puede desprenderse de algunos textos no firmados por Calvino pero de atribución casi cierta: nos referimos a algunas presentaciones de las diferentes colecciones de la editorial Einaudi presentes en el Catalogo generale editado en $1956^{13}$. Además de presentar algunas colecciones basadas en los clásicos tradicionales (de Goethe a Conrad o Dickens) o centradas en autores contemporáneos afirmados como Hemingway o Sartre, Calvino reflexiona acerca de algunos nudos centrales de su teorización poética de aquellos años como, por ejemplo "il grande motivo di gelosia [...] degli scrittori contemporanei per i loro colleghi del secolo precedente" (pág. 185), un modo de referirse a la nostalgia y crisis de la novela "di vaste dimensioni" (pág. 63). Así se explica el nacimiento de una colección como "I Gettoni", surgida en 1951 de "l'esigenza di una collana narrativa esclusivamente 'sperimentale”" (pág. 53). No por casualidad, el último volumen publicado en dicha colección en aquel año era precisamente La biblioteca di Babele (la aludida traducción de Ficciones llevada a cabo por Franco Lucentini), comentado de esta forma por Calvino: "L'argentino Borges è forse lo scrittore fantastico piú allucinato e grottesco dopo Kafka” (pág. 74). En el contexto cultural italiano 
de aquellos años, la inclusión de un texto narrativo no novelístico y perteneciente a un filón fantástico opuesto al realismo era un acto de valentía intelectual que Calvino no podía afrontar todavía de forma decidida ${ }^{14}$, como hemos tratado de demostrar resumiendo la trabajada evolución de su poética, si bien el agotamiento de su vena puramente realista y el fracaso del proyecto de "gran novela" pueden ser ya dados por descontados en 1956, síntomas del inicio de un cambio expresado con claridad en "Il mare dell'oggettività" (1959) y en cuya maduración el magisterio borgeano fue sin duda importante.

En mayo de 1959, algunos meses antes de la redacción del mencionado ensayo, la revista Nuovi Argomenti publicó un cuestionario sobre la situación de la novela y otros aspectos de la entonces debatida crisis del género. La respuesta de Calvino a una de las preguntas, relativa a la novela ensayística y a la posible sustitución de Hemingway por Musil, nos sumerge de lleno en lo dicho hasta ahora:

"E' naturale però che ci sia oggi anche una narrativa che si pone come oggetto le idee, la complessità delle suggestioni culturali contemporanee ecc... Ma a farlo riproducendo delle discussioni di intellettuali su questi argomenti, c'è poco sugo. Il bello è quando il narratore da suggestioni culturali, filosofiche, scientifiche ecc... trae invenzioni di racconto, immagini, atmosfere fantastiche completamente nuove; come nei racconti di Jorge L. Borges, il più grande narratore 'intellettuale' contemporaneo" (S I, págs. 1525-1526).

Como puede apreciarse, a las puertas de la nueva década, Borges aparece ya ante Calvino como un modelo canónico de narrativa declaradamente fantástica e intelectual, un género a cuya aceptación por parte del italiano no son ajenos sin duda el proyecto einaudiano Fiabe italiane (aparecido en 1956, tras dos años de duro trabajo) ${ }^{15}$ y la relectura de un poeta como Ariosto, destinado a convertirse en esos años en el modelo de escritor calviniano encargado de construir un género nuevo sobre los escombros de una épica ya inviable, empeñado en transfigurar en clave irónica e intelectual una realidad magmática y compleja.

En efecto, dos años más tarde, el escritor argentino vuelve a aparecer mencionado como paradigma de un género fantástico-científico y creador de un estilo inconfundible. En una carta dirigida a Primo Levi en noviembre de 1961, Calvino juzga algunos relatos "fantabiológicos" de dicho escritor (en cuya descripción no es difícil adivinar cierta semejanza con la génesis de los relatos cosmicómicos calvinianos), señalando la falta de un timbre exclusivamente personal y aduciendo como modelo de literatura fantástica precisamente al escritor argentino, creador de una cifra estilística y poética ("Naturalmente, ti manca ancora la sicurezza di mano dello scrittore che ha una sua personalità stilistica compiuta; come Borges, che utilizza le suggestioni culturali piú disparate e trasforma ogni invenzione in qualcosa che è esclusivamente suo, quel clima come rarefatto che è come la sigla che rende riconoscibile le opere di ogni grande scrittore", LDA, pág. 382).

$\mathrm{Al}$ año siguiente aparecerá otro de los textos fundamentales del Calvino teorizador, "La sfida al labirinto" (1962), cuyo título alude ya a uno de los principales motivos borgeanos. En dicho ensayo se hace hincapié en las semejanzas existentes entre ciencia y literatura, entendidas como posibilidades gnoseológicas y se sistematizan las diferentes corrientes de vanguardia típicas del siglo. Destaca entre ellas una línea racionalista antipsicologista y ocupada en desafiar el laberinto de la realidad, una línea en la que destaca, cómo no, el nombre de Borges, creador de un "labirinto delle immagini culturali di una cosmogonia piú labirintica ancora" (S I, pág. 121). Es preciso observar cómo a la caracterización intelectual y fantástica de la obra del argentino se añade ahora una explicación del origen del laberinto de lo real, es decir, una imagen global del mundo tanto desde un punto de vista temporal como espacial ${ }^{16}$, un proyecto emparentado sin duda con los relatos cosmicómicos 
que verán la luz en 1965 pero cuya redacción se remonta en algunos casos hasta el 63. El mismo Calvino hará explícita nuestra hipótesis: en noviembre del 64, la revista Il Caffé politico e letterario publicó cuatro de los relatos que aparecerían al año siguiente en volumen, acompañados de una nota autocrítica del autor en la que se trazaba una rápida reseña de posibles antecesores como Leopardi, los comics de Popeye, Beckett, Giordano Bruno, Lewis Carroll, ejemplos de artes figurativas y, en ocasiones, Landolfi, Kant y Borges (RR II, pág. 1322) ${ }^{17}$.

Mientras tanto, la evolución poética calviniana sigue su curso y se apresta a entrar en la estación lógico-matemática y combinatoria típica de los años 65-80. A la concepción "intelectual” de la literatura, basada en una transfiguración fantástica de la realidad a partir de las más dispares sugestiones culturales, se le suma una conciencia formal exacerbada en abierta oposición a la interioridad, a la presencia del self. En 1967 aparece el ensayo "Tra idee e fantasmi”, una nueva reelaboración de las relaciones entre literatura, filosofía y ciencia que rinde homenaje a la tríada Lewis Carroll, Raymond Queneau, Jorge Luis Borges ("i grandi degustatori di filosofia come stimolo alla immaginazione”, S I, pág. 195): si Carroll había abierto el camino a una nueva relación entre literatura y filosofía, Queneau y Borges pueden ser considerados sin duda los dos autores que más contribuyeron a la gestación del Calvino abstracto, combinatorio y geométrico, cuya poética se resume en dos textos como "Cibernetica e fantasmi (Appunti sulla narrativa come processo combinatorio" (1967) y "La macchina spasmodica" (1969).

Con los años 70, años de crisis creativa para Italo Calvino, encerrado en un silencio que va desde Il castello dei destini incrociati (1973) hasta Se una notte d'inverno un viaggiatore (1979), parece disminuir el recurso a Borges como paradigma de una poética determinada. Más que en un eventual desinterés, creemos necesario pensar en una asimilación tan profunda que exige una labor más imaginativa que crítica, una aplicación concreta del magisterio borgeano (significativos a este respecto Il castello... o Le città invisibili, aparecido en 1972). De hecho, las menciones del argentino son bastante numerosas en esta década, si bien cualitativamente distintas de las ya examinadas, pues se reducen en su mayor parte a citas puntuales de la obra borgeana (en general no especificadas) tomadas a modo de ejemplo con la intención de ilustrar algunas afirmaciones del italiano ${ }^{18}$. Dicha actitud por parte de Calvino parece reflejar una idea de la obra de Borges como suma erudita, serie de referencias y alusiones múltiples y especulares donde lo importante no es tanto el valor de verdad cuanto las capacidades evocadoras de la imagen, una perspectiva ésta muy borgeana y en absoluto ajena a la gestación de la metanovela $\mathrm{Se}$ una notte... (1979). Un año antes de la aparición de dicho texto, en una ponencia titulada "I livelli di realtà in letteratura", leída en un congreso interdisciplinar sobre niveles de realidad, Calvino reflexiona sobre las diferentes instancias narrativas presentes en los textos literarios, aludiendo al enchâssement o narración encajada en un marco y citando a Borges y su mención de la mágica y circular noche $602^{\text {a }}$ de Las 1001 noches (S I, págs. 394-395) ${ }^{19}$. Si tenemos en cuenta que la estructura marco/narraciones encajadas de Las 1001 noches será una de las bases formales de Se una notte... y que en dicho libro se recurre en repetidas ocasiones al relato especular (mise en abyme), no será difícil concluir que la relectura de la obra borgeana desempeñó un papel no secundario en la resolución de la crisis creativa calviniana de la segunda mitad de los años 70 .

Nos referimos concretamente a una noción de literatura como palimsesto o amasijo de citas en el que la idea de autoría se desvanece, temas todos ellos centrales en la metanovela del 79. El mismo Calvino confirmará lo dicho cuando, en respuesta a una reseña de Angelo Guglielmi a Se una notte..., se referirá a Edgar 
Allan Poe y a Borges como precursores de la concepción literaria subyacente a uno de los incipit incluidos en su novela, "In una rete di linee che si intersecano", que funciona a modo de mise en abyme del texto calviniano (“...un esempio di narrazione che tende a costruirsi come un'operazione logica o una figura geometrica o una partita a scacchi. [...] ...potremmo rintracciare il padre piú illustre di questo modo di raccontare in Poe e il punto d'arrivo piú compiuto e attuale in Borges", Calvino, 1979: pág. 4) ${ }^{20}$.

Una combinación (Poe-Borges) destinada al éxito, pues Calvino recurrirá a ella en repetidas ocasiones durante la primera mitad de los años 80 (morirá en 1985), un periodo en el que la poética del italiano seguirá derroteros un poco diferentes, si bien su reflexión teórica se cifrará claramente en el proyecto de recapitular las influencias más significativas en su obra, sistematizadas al hilo de su propia poética, una especie de árbol genealógico o panteón artístico en el que hallar morada y donde la presencia del argentino es constante ${ }^{21}$.

En este periodo, el "borgismo" de Calvino había pasado ya a ser casi un lugar común de la crítica, como demuestran las diferentes entrevistas concedidas por el italiano en esos años. En febrero de 1981, al ser interrogado acerca de la influencia de Borges en su obra, Calvino responde de la siguiente forma:

"Borges è stato per me di un'importanza straordinaria. La lettura di Borges è servita a mettere in luce delle cose che però erano già nel mio gusto, nella tendenza della mia immaginazione. Mi lega a Borges l'ammirazione per certi autori inglesi che lui ama, per esempio, per Stevenson, Kipling o Chesterton: tutte cose che mi piacevano prima di leggere Borges. Naturalmente, io vengo da tutta un'altra storia, quella di un giovane europeo ch'è stato un po' figlio della seconda guerra mondiale... e sono partito anche con delle coordinate culturali molto diverse. Però come Borges io amo in genere gli autori che nel fantastico hanno il gusto della geometria mentale... e cerco di appartenere a questa costellazione" (Tamponi, 1981; la cursiva es nuestra). Además de la admisión explícita de la influencia borgeana y de su adscripción a la galaxia de escritores fantástico-geométrico-intelectuales, elementos todos ellos madurados en los años 50-70, nos interesa notar aquí un significativo cambio de actitud: Calvino subraya una comunidad de fondo con el argentino anterior incluso a su lectura y para certificarla acude a una serie de autores clásicos. Implícitamente, el italiano se está poniendo a la altura de todos esos nombres, en un intento de incluirse como último episodio de esa progenie literaria que iría de Stevenson a él mismo, pasando por el escritor bonaerense ${ }^{22}$.

En la misma línea, destaca la ponencia leída en el congreso sevillano de la UIMP sobre literatura fantástica (celebrado en 1984, con la participación, entre otros, del mismo Borges). En dicho texto, Calvino considera la vena fantástica italiana como un intento fallido, definiendo dicho género a partir de Leopardi y llevando claramente el agua a su molino al darle las características típicas de su propia obra, basada a su vez en tres modelos: Beckett, Borges

("che mi apre un mondo fantastico di perfetta limpidezza in cui mi pare d'aver abitato da sempre ma che non cessa di sorprendermi"; S II, pág. 1680; la cursiva es nuestra) y Kafka ${ }^{23}$.

Ese mismo año, en un artículo dedicado al fallecido crítico y escritor italiano Emilio Cecchi, Calvino prosigue su labor de sistematización canonizadora, estableciendo un, cuando menos, inesperado paralelo entre dicho autor y Borges (del que Calvino vuelve a declararse un "fedele"), de nuevo a través de clásicos anglosajones como Stevenson o Conrad que funcionarán a modo de "modelli comuni” de los tres (S I: pág. 1037). De esta forma, la pareja Cecchi-Borges se convierte en la tríada Cecchi-Borges-Calvino, un paso más en el proceso calviniano de definición-dignificación. Por esta vía de alusiones, contraposiciones y deudas, se llegará a una figura única que en sí misma puede funcionar como consecuencia y 
punto de partida del género fantástico y, en última instancia, como modelo de los modelos de Calvino.

En 1983, en la introducción a una antología de relatos fantásticos a su cuidado (Racconti fantastici dell'Ottocento), Calvino traza un sucinto panorama del género, estableciendo en Hoffmann y Poe, los dos autores más influyentes, un juicio (el referido al escritor americano) que había expresado ya en 1980 en un artículo dedicado a Dino Buzzati, donde se afirmaba que Poe había sido el modelo supremo de su adolescencia y se consideraba la posibilidad de que siguiera siéndolo en ese momento. Cuatro años más tarde, el tono dubitativo de Calvino ha sido sustituido por una total seguridad acerca del papel de Poe en su evolución literaria. En una entrevista concedida en 1984 y construida en torno al tema de la cultura americana, el italiano vuelve a señalar a Edgar Allan Poe como la influencia más importante localizable en su obra. Además, en una operación típicamente calviniana, teje con maestría una delgada tela de araña que relaciona al autor americano con sus otros modelos, volviendo a crear así una genealogía cuyo último lugar cronológico le correspondía implícitamente,:

“...oggi se dovessi dire qual è l'autore che mi ha influenzato di più, non solo in ambito americano, ma in senso assoluto, direi che è Edgar Allan Poe, perché è uno scrittore che, nei limiti del racconto, sa fare di tutto. [...] Per questo si possono tracciare delle linee che collegano Poe, per esempio, a Borges, o a Kafka” (S II, pág. 2906).

Así pues, de nuevo un Borges utilizado como piedra de toque para poner de manifiesto en otros autores aspectos importantes a la hora de determinar la filiación de la propia poética.

Llegados a ese punto, los tiempos estaban maduros para dedicar un ensayo a la figura del argentino. El viaje de Borges a Italia en octubre del 84 será el pretexto ideal. En el discurso pronunciado en su honor por Calvino, el más citado por la crítica junto a las conferencias americanas, hallamos una sistematización sintética de los diferentes aspectos del interés calviniano por Borges que hemos intentado rastrear en estas páginas. Como de costumbre, el italiano traza una imagen poética del escritor tratado, relativa a los puntos concomitantes con su propias inquietudes. No en vano, los rasgos subrayados en este caso son la idea de literatura intelectual (cuya gestación en Calvino hemos examinado), la vocación de la escritura breve, la concepción potencial y combinatoria del texto (a decir verdad, más visible en ciertos temas borgeanos que en los apectos formales de su obra) y la presencia del infinito espacio-temporal. Ahora bien, es preciso subrayar que, al borrar cualquier alusión cronológica al proceso de asimilación de Borges por su parte, Calvino pone de manifiesto una comunidad de intereses y de proyectos literarios de fondo que le permita entrar en la misma constelación de escritores en calidad de par y no de epígono o secuaz, una actitud bien visible también en Lezioni americane, verdadero testamento literario del autor del que emerge la figura de un escritor-modelo donde es difícil distinguir a Calvino de su propia idea de Borges (algo especialmente visible, por ejemplo, en el capítulo "Molteplicità", el más trabajado en su composición y sin duda el de mayor peso literario). De esta forma, el escritor italiano se preparaba a entrar en el nuevo milenio (como reza el subtítulo de su libro póstumo) de la mano de los autores canónicos, facilitando la labor de los críticos y estudiosos posteriores al entregarles un mapa pormenorizado de su propia ubicación en el panteón de los clásicos. 
4.

Veinte años después de la muerte de Calvino, es legítimo preguntarse hasta qué punto su ansiada canonización se ha hecho realidad y, de ser así, si la misma se ha producido de la forma deseada por el escritor italiano. Uno de los principales índices del nivel de canonización de un escritor, su presencia en las antologías escolares, puede darnos algunas indicaciones al respecto. Paolo Giovannetti, tras haber examinado la distribución de la obra calviniana en las actuales antologías de la escuela media y superior italiana, hace hincapié en la polarización entre un Calvino neorrealista (años 40-50) y un Calvino postmoderno (el autor de Palomar o Se una notte..., para entendernos) con una atención preponderante por este último, situación que el autor califica de "deprimente" ya que, a su juicio, deja en segundo lugar valores como la edificación o el diálogo con el gran público, típicos del Calvino más comprometido (Giovannetti, 1993: pág. 68). Más allá de consideraciones ideológicas, dicha operación muestra bien a las claras el éxito de la estrategia calviniana de canonización examinada en estas páginas (y en la que la presencia de Borges no es secundaria), esa labor cosmética de autoconstrucción a posteriori que tanto irrita a la crítica comprometida italiana, empeñada en reivindicar los aspectos calvinianos oscurecidos cuando no eliminados por el mismo autor.

Otro indicador del triunfo de semejante estrategia podemos hallarlo, por ejemplo, en el libro de Harold Bloom dedicado precisamente al canon occidental. En dicho volumen, Borges (el Borges narrador y ensayista) recibe un tratamiento de favor, siendo considerado "el fundador primordial de la literatura hispanoamericana” (Bloom, 1994: pág. 476) y uno de los clásicos del siglo XX (que Bloom denomina Edad Caótica). Por otra parte, en uno de los Apéndices el autor lleva a cabo una especie de "profecía cultural" al elaborar una lista dividida por países o áreas geográficas de autores y obras de los últimos cien años destinados según su opinión a sobrevivir con toda probabilidad en el canon occidental. Es significativo constatar que en la parte dedicada a Italia, junto a textos de autores como Montale, Ungaretti, Pirandello o Pavese, aparece también Italo Calvino (el más joven de los incluidos, junto con Antonio Porta) con cuatro de sus obras, a saber: Il barone rampante (1959), Ti con zero (1967), Le città invisibili (1972) y Se una notte d’inverno un viaggiatore (1979) (Bloom, 1994: pág. 556). En otras palabras, el Calvino canónico esponsorizado durante años por el Calvino teórico, con un predominio de los aspectos fantásticos, cosmogónicos, combinatorios y, añadiríamos nosotros, borgeanos. No por casualidad, en los últimos diez años la pareja BorgesCalvino aparece en numerosas ocasiones en escritos pertenecientes a disciplinas dispares para indicar una concepción literaria representativa de ciertos aspectos de la era posmoderna, deconstructiva y digitalizada ${ }^{24}$.

Último y sintomático episodio de la eficaz canonización del autor italiano puede considerarse la reciente polémica que se desencadenó entre la crítica italiana con motivo de la publicación del libro de Carla Benedetti dedicado a Pasolini y Calvino como autores paradigmáticos de dos opuestas concepciones de la literatura en el seno de la sociedad (Benedetti, 1998). En una entrevista concedida por la autora al diario Corriere della sera, poco antes de la publicación de su ensayo, se trazaba una idea degradante de Calvino precisamente en cuanto autor "canonizzato come classico 
ancora in vita" (Fiori, 1998) y se hacía hincapié en la importancia del impulso calviniano en dicha canonización (ideas todas ellas presentes en Benedetti, 1998: 24). El autor italiano aparecía así como una especie de sátrapa de la industria literaria ocupado en "un'autopromozione costante" (Fiori, 1998), un representante de una "letteratura depotenziata" (ibid.), basada exclusivamente en el formalismo y la inteligencia, una idea ésta desarrollada en el libro de Benedetti, que opone a un Calvino "autore immagine" un Pasolini "autore in carne e ossa". A raíz de dicha entrevista, los defensores de la poética combinatoria calviniana (la idea "dominante" de literatura, como la denomina Benedetti) y los nostálgicos de la literatura "tutta anima e cuore" se enzarzaron en una bagarre intelectual en la que el libro de Benedetti pasó a un segundo plano en beneficio de un proceso sumario a la idea de literatura "pura" (no en vano, apologistas y detractores del escritor italiano mencionaron a Borges y Queneau, entre otros, como padres espirituales de la poética calviniana) ${ }^{25}$. Si en el ámbito de tan estéril discusión se salvan sólo algunas intervenciones, cuando menos articuladas (Giovanardi, 1998; Tabucchi, 1998; Asor Rosa, 1998), es significativa la contribución del crítico Angelo Guglielmi quien, aprovechando la polémica, llamó la atención sobre la necesidad de trazar un balance final del siglo literario, una especie de curriculum escolar con aprobados y suspensos (de escritores canónicos o menores, en otras palabras). Guglielmi coloca a Pasolini, Moravia y Pratolini entre los perdedores, situando a Calvino en la rosa de los vencedores (convalidando de esta forma el punto de partida de Carla Benedetti), junto a autores como Carlo Emilio Gadda, Joyce, Faulkner, Kafka y, por supuesto, Jorge Luis Borges (Guglielmi, 1998). Una gloria compartida que, sin duda, hubiera hecho las delicias del propio Calvino, el cual hubiera visto definitivamente coronados los esfuerzos de una empresa canonizadora cuyo perfil hemos intentado describir en estas páginas.

\section{Ediciones y siglas utilizadas}

Las citas relativas a la obra de Italo Calvino remiten a las siguientes ediciones: Saggi (1945-1985), a cargo de Mario Barenghi, Milán, PalomarMondadori, 1995, Vol. I (S I), Vol. II (S II).

I libri degli altri. Lettere (1947-1981), edición de Giovanni Tesio, Turín, Einaudi, 1991 (LDA)

Las citas relativas a la obra de Jorge Luis Borges remiten a las siguientes ediciones: Obras completas. I (1923-1949), Barcelona, Emecé, 1989 (OC I)

Obras completas. II (1952-1972), Barcelona, Emecé, 1989 (OC II) Obras completas. IV (1975-1988), Barcelona, Emecé, 1996 (OC IV)

\footnotetext{
${ }^{1}$ El texto apareció parcialmente en el diario la Repubblica (16 de octubre de 1984) con el título "I gomitoli di Jorge Luis". La versión integral apareció en el volumen póstumo Perché leggere i classici (Milán, Mondadori,1991, págs. 292-301). Ahora en S, I, págs. 1292-1300 (por lo que respecta a las siglas referidas a las obras de Calvino y Borges citadas en el presente trabajo, remitimos al lector a la sección bibliográfica conclusiva, concretamente la titulada "Ediciones y siglas utilizadas").
} 
${ }^{2}$ Por lo que respecta a la cronología y modalidades de la fortuna literaria de Borges en Italia, nos permitimos hacer alusión a nuestro anterior trabajo (Santos Unamuno, 1996).

${ }^{3}$ Un parecer semejante al de Mclaughlin lo expresa Marina Polacco, que considera Se una notte d'inverno un viaggiatore el libro más borgeano de los escritos por Calvino. La estudiosa italiana cifra la presencia de Borges en 5 rasgos presentes en la citada novela: invención de escritores y países imaginarios, el motivo del escritor atemporal y anónimo, el tema de la copia (la reescritura al estilo de Menard), el motivo de la falsificación y el apócrifo, el tema de la búsqueda de un libro sagrado e infinito, un librototal y el motivo de la biblioteca (Polacco, 1991: 1007-1019).

${ }^{4}$ El congreso aludido, que tuvo lugar en San Remo entre el 28 de noviembre y el 1 de diciembre de 1996, llevaba por título "Italo Calvino: a writer for the next millennium". Las actas del mismo no han sido publicadas aún. Agradecemos al profesor Crovetto su disponibilidad a la hora de procurarnos el texto de su ponencia, titulada "Il castello dei destini che si biforcano" (Crovetto, 1996).

${ }^{5}$ En una carta dirigida al crítico Guido Fink en 1968, como consecuencia de una reseña a Ti con zero publicada por éste en la revista Paragone, Italo Calvino afirmaba: "Da giovane la mia aspirazione era diventare uno 'scrittore minore'.[...] Ma era già un criterio sbagliato, perché presuppone che esistano dei 'maggiori'”(Calvino, 1985: pág. 8). Nótese la proverbial reticencia e ironía calviniana al negar aparentemente la existencia de un canon literario, desmentida por lo demás con su propia obra y en múltiples ensayos centrados en la lección de los clásicos. Guido Bollati, compañero de fatigas de Calvino en la editorial Einaudi, narra asimismo que en 1970-71 Calvino le dijo, fingiendo bromear: "Sono un minore. E’ importante essere un minore” (Bollati, 1993: pág. 2). De nuevo la ironía del italiano, que ya en aquella época iba eligiendo a sus mentores literarios, aplicándose aquello del "dime con quién andas y te diré quién eres”.

${ }^{6}$ Bruns, G. L., "Canon and Power in the Hebrew Scripture", en Von Hallberg, R. (ed.), Canons, Chicago, Chicago University Press, 1984, pág. 67 (citado en Landow, 1992: págs. 183-184).

${ }^{7}$ Se trata de teorías que Bloom había aplicado hace un cuarto de siglo al fenómeno de la influencia poética, mencionando en dos ocasiones al mismo Borges y su idea de escritor epígono que crea a sus ancestros literarios, expresada en "Kafka y sus precursores" (OC II, págs. 8890)(Bloom, 1973: 27 y 147).

${ }^{8}$ Dichos aspectos de la operación literaria calviniana son examinados en las actas del Congreso dedicado a Calvino y el mundo editorial, celebrado en 1990 (Clerici-Falcetto eds., 1993). Por lo que respecta al "clasicismo" de Calvino, es fundamental un texto como "Italiani, vi esorto ai classici”, publicado en la revista L'Espresso en 1981, en pleno proceso de “autocanonización" (ahora con el título "Perché leggere i classici”, en $S$ II, págs. 1816-1824).

${ }^{9}$ Michel Lafon afirma tajantemente: "Calvino découvre Borges en 1953 et dès lors ne cesse de le lire, de le saluer, de le citer, de le commenter" (Lafon, 1996: pág. 11), sin dar, por lo demás, ulteriores indicaciones respecto a dicha afirmación. Giuseppe Nava conjetura erróneamente que Calvino leyó a Borges gracias a la traducción de Lucentini (Nava, 
1996: págs. 67-68). Por lo que respecta a la alusión calviniana a su trabajo en la editorial Einaudi, hay que precisar que Calvino fue contratado regularmente como empleado a partir de enero de 1950, si bien el inicio de su relación con la empresa es anterior y se remonta concretamente a 1945 (Tesio, 1991: p. IX; Bollati, 1993: págs. 4-5; Ferrero, 1993: pág. 178).

${ }^{10}$ La fórmula "scrittore artigiano" fue acuñada por Calvino en un artículo publicado en L'Unità de Milán el 4 de noviembre del 47, refiriéndose al narrador estadounidense Sherwood Anderson. En dicho artículo se menciona a Hemingway como pionero de esta corriente (S I, págs. 12831285).

${ }^{11}$ Significativa a este respecto la intención de Calvino de entrar en la "Gran Polémica" desatada en 1947 en las páginas de Il Politecnico de Elio Vittorini a propósito de la relación entre política y cultura. En una carta dirigida a Vittorini y fechada el 12 de diciembre de 1947 Calvino incluyó una nota sobre Hemingway (nunca publicada a causa de la inmediata desaparición de la revista) como ejemplo de nuevo escritor basado en "una moralità nell'impegno" y "una libertà nella responsabilità" (LDA, pág. 7). Otros textos fundamentales en la enunciación de estas ideas son "Umanesimo e marxismo" (1946), “'Laboratorio dell'uomo' di Felice Balbo (Marxismo e cattolicismo)" (1947), "Ingegneri e demolitori" (1948) y "Saremo come Omero" (1948), todos ellos incluidos en S I.

${ }^{12}$ Entre muchos otros ejemplos posibles, hemos seleccionado el siguiente fragmento perteneciente a una carta dirigida el 7 de marzo de 1956 a Valerio Bertini: “...oggi nella letteratura progressista, [...] la pretesa di fare il romanzo è una grossa catena al piede che ci portiamo dentro. [...] Il romanzo è una piaga della letteratura socialista. Guarda come l'esperienza dell'Urss è andata diluita in una miriade di romanzi melensi. I pochi libri che restano saranno quelli che rifiutano la struttura del romanzo. Io voglio proprio fare una crociata per distogliere da questa limitazione la letteratura socialista” (LDA, págs. 178-179).

${ }^{13}$ Catalogo generale delle edizioni Einaudi dalla fondazione della casa editrice al $1^{\circ}$ gennaio 1956, Turín, Einaudi, 1956. Luca Baranelli, en su bibliografía relativa a los textos editoriales de Italo Calvino (que incluye contraportadas y otros géneros paratextuales en su mayor parte no firmados), atribuye a éste las presentaciones de las siguientes colecciones: "Narratori stranieri tradotti", "I coralli", "Supercoralli", "I gettoni", "Narratori contemporanei", "Nuova Atlantide" y "Piccola biblioteca scientifico-letteraria” (Baranelli, 1993: pág. 289; 1994: págs. 1425-1426).

${ }^{14}$ Buena prueba de ello es la actitud de disculpa y matización típica de Calvino a raíz de las polémicas surgidas al hilo de libros "fantásticos" como Il visconte dimezzato (1952) o Il barone rampante (1957).

${ }^{15} \mathrm{La}$ importancia de dicha experiencia en el recorrido calviniano es analizada por diferentes autores en Frigessi ed. (1988).

${ }^{16}$ Precisamente una de las características que Calvino consideraba necesarias para convertirse en un clásico, como se deduce del punto No 10 del mencionado "Italiani, vi esorto ai classici" (1981): "Chiamasi classico un libro che si configura come equivalente dell'universo, al pari degli antichi talismani” (S II, pág. 1821).

${ }^{17}$ Dicha nota aparecerá reproducida en la contraportada de Cosmicomiche vecchie e nuove (publicado un año antes de la muerte de Calvino, en plena fase final canonizadora), que recogerá en un solo volumen todos 
los relatos del ciclo cosmicómico, incluyendo los de Ti con zero y otros, escritos en los años 70 y 80 .

${ }^{18}$ Un ejemplo aislado lo tenemos en 1971, en la introducción al volumen de historias populares de Francesco Lanza, Mimi siciliani, Palermo, Esse/Sellerio, VII-XX. Al referirse a la falta de descripciones de la Naturaleza en dichas historias campesinas, Calvino comenta: "Il contadino è tanto immerso nella natura che non ha bisogno di parlarne, cos̀̀ come nel Corano non si parla mai di cammelli (il che prova -scrisse una volta Borges- che veramente fu dettato negli accampamenti del deserto)" (S II, 1608). Sin duda, Calvino se refiere al ensayo de Borges "El escritor argentino y la tradición", incluido en Discusión (1932), donde se puede leer: "He encontrado días pasados una curiosa confirmación de que lo verdaderamente nativo suele y puede prescindir del color local; encontré esta confirmación en la Historia de la declinación y caida del Imperio Romano de Gibbon. Gibbon observa que en el libro árabe por excelencia, en el Alcorán, no hay camellos: yo creo que si hubiera alguna duda sobre la autenticidad del Alcorán, bastaría esta ausencia de camellos para probar que es árabe" (OC I, 270).

${ }^{19}$ Son dos las fuentes calvinianas más probables. En "Los traductores de las 1001 noches", incluido en Historia de la eternidad (1936), a propósito de repeticiones con valor poético, Borges se pregunta: "¿No es portentoso que en la noche 602 el rey Shahriar oiga de boca de la reina su propia historia? A imitación del marco general, un cuento suele contener otros cuentos, de extensión no menor: escenas dentro de la escena como en la tragedia de Hamlet, elevaciones a potencia del sueño" (OC, I, 413). En el ensayo "Magias parciales del Quijote", incluido en Otras inquisiciones (1952), se dedica una página entera a la mise en abyme, mencionando el propio Quijote, de nuevo el Hamlet, el Ramayana, y una vez más las 1001 noches: "Es conocida la historia liminar de la serie: el desolado juramento del rey, que cada noche se desposa con una virgen que hace decapitar en el alba, y la resolución de Sharazad, que lo distrae con fábulas, hasta que encima de los dos han girado mil y una noches y ella le muestra su hijo. La necesidad de completar mil y una secciones obligó a los copistas de la obra a interpolaciones de todas clases. Ninguna tan perturbadora como la de la noche DCII, mágica entre las noches. En esa noche, el rey oye de boca de la reina su propia historia" (OC II, 46-47). Casi con total seguridad podemos considerar este fragmento como la fuente de Calvino, quien repite las palabras de Borges evidenciadas por nosotros en cursiva cuando define la noche 602a "magica tra tutte" (S I, 394).

${ }^{20} \mathrm{El}$ carácter "borgeano" de Se una notte... es refrendado de nuevo por Calvino en el mismo artículo, cuando afirma que la relectura del relato "El acercamiento a Almotásim" le permitió concebir el propio texto (ya concluido) "come quella che avrebbe potuto essere una ricerca del 'vero romanzo' e insieme del giusto atteggiamento verso il mondo, dove ogni 'romanzo' cominciato e interrotto corrispondeva a una via scartata' (Calvino, 1979: pág. 5). En otro texto de 1980, "Furti ad arte", referido a la obra gráfica de Tullio Pericoli, Calvino, tras haber trazado un paralelo entre artes figurativas y literatura como actividades basadas en el latrocinio de temas y motivos, confiesa de nuevo su deuda con respecto 
a Borges en algunos motivos de Se una notte... "robados" al argentino (S II, pág. 1809).

${ }^{21}$ Muy numerosos los ejemplos. En 1980, en un artículo-recensión de una exposición del Centre Pompidou dedicada a la cartografía, "Il viandante invisibile sulle strade della Terra" (la Repubblica, 18 de junio 1980; incluido en el volumen Collezione di sabbia, en 1984; ahora en S I, 426433), se menciona "il racconto di Borges, della carta dell'Impero cinese che coincideva con l'estensione dell'Impero” (S I, 432). En 1981, en un artículo publicado en la Repubblica (2-3 de agosto), "Che noia in Paradiso", se recensiona una de las conferencias borgeanas de Oral, concretamente la dedicada a Swedenborg. Calvino resalta la vocación combinatoria de Borges, "la costruzione d'una vita dell'al di là tutta simmetria e concretezza, un modello ordinato in cui tanto i viventi quanto i defunti possano scegliere i loro destini senza mai turbare l'ordine generale" (Calvino, 1981). En una recensión a un libro policíaco de Fruttero \& Lucentini ("Se un fantasma corre il Palio", la Repubblica, 13-14 de noviembre de 1983) Calvino habla de una trama metafísica “degna di Borges” (S I, 1066). En 1984, en un artículo dedicado al libro de Georges Perec, La vie mode d'emploi, se menciona a Borges como uno de los clásicos y maestros de Perec cuyas citas aparecen camufladas en el texto (S I, 1397). En 1984, en una recensión a una antología de relatos fantásticos, se menciona "Il pilota cieco" (1907), un relato de Giovanni Papini, "quel Papini giovanile caro a Borges che di lì prese le mosse, tutto esattezza e negatività, così diverso dal Papini che abbiamo conosciuto poi”. Calvino se refiere sin duda al volumen de relatos de Papini elegidos por Borges, perteneciente a la colección "La Biblioteca di Babele" (ver también el prólogo al volumen de Papini incluido en la 'Biblioteca personal', en el que aparece "El piloto ciego" junto con otros dos relatos; Biblioteca personal (prólogos), Madrid, Alianza Tres, 43-44; ahora en OC IV, 472-473).

${ }^{22}$ Una actitud ésta que Harold Bloom considera típica en los fenómenos de influencia poética: en un momento determinado, el sucesor alaba al precursor por haber sido lo que dicho sucesor es en ese momento (Bloom, 1973: 131).

${ }^{23}$ Recordemos que la pareja Borges-Kafka aparecía ya en la presentación de La biblioteca di Babele de la editorial Einaudi (1956), cuando el argentino era todavía un desconocido en Italia y necesitaba padrinos literarios para ser absorbido.

${ }^{24}$ Desde diferentes posiciones (favorables, contrarias o neutras), algunos autores han hablado de Borges y Calvino como precursores de una literatura posmoderna e hipertextual que mina algunos presupuestos de la cultura de la imprenta (Varsava, 1990: passim; Bolter, 1991: págs. 165178; Santos Unamuno, 1995: passim; Merrell, 1997: pág. 67; De Carli, 1997: págs. 76 y 111).

${ }^{25}$ Añadiremos, de pasada, que dicha polémica no hacía sino retomar algunos aspectos de la discusión suscitada en los años 80 por los detractores de un Calvino "excesivamente borgeano" (acerca de esta discusión, véase Paoli, 1997: pág. 40), una imagen creada y gestionada por el mismo autor, como hemos visto. 


\section{Bibliografía}

Asor Rosa, A.: (1998) "Il triangolo dei Narcisi", la Repubblica, 21 de enero.

Baranelli, L.: (1993) "Italo Calvino e l'editoria. Bibliografia", en ClericiFalcetto eds., págs. 279-302.

(1994) "Bibliografia degli scritti di Italo Calvino", en Calvino, Italo, Romanzi e racconti. Vol. III. Racconti sparsi e altri scritti d'invenzione, edición de Mario Barenghi y Bruno Falcetto, Milán, Mondadori, págs. 1351-1516.

Benedetti, C.: (1998) Pasolini contro Calvino. Per una letteratura impura, Milán, Bollati Boringhieri.

Bernés, J. P.: (1993) "Introduction. Portraits et autoportraits", en Borges, J. L., Euvres complètes, edición de J.P.Bernès, París, Gallimard, págs. XIII-XXVIII.

BERTONE, G.: (1994) Italo Calvino. Il castello della scrittura, Turín, Einaudi. Bloom, H.: (1973) The Anxiety of Influence, Oxford, Oxford University Press (L'angoscia dell’influenza. Una teoria della poesia, Milán, Feltrinelli, 1983).

(1994) The Western Canon. The Books and School of the Ages, Nueva York, Harcourt Brace \& Co. (El canon occidental. La escuela y los libros de todas las épocas, Barcelona, Anagrama, 1995).

Bollati, G.: (1993) “Calvino editore”, en Clerici-Falcetto eds., págs. 1-19. Bolter, J. D.: (1991) Writing Space. The Computer, Hypertext and the History of Writing, Hillsdale-Hove y Londres, Lawrence Erlbaum (Lo spazio dello scrivere. Computer, ipertesti e storia della scrittura, Milán, Vita e Pensiero, 1993).

Calvino, I.: (1979) "Se una notte d'inverno un narratore", Alfabeta, año $1, \mathrm{n}^{\circ} 8$, diciembre, págs. 4-5.

(1981) "Che noia in Paradiso", la Repubblica, 2-3 de agosto.

(1984) “'Scrittori esemplari, vi odio tutti”', L'Unità, 20 de setiembre.

(1985) "Lettera di uno scrittore 'minore' (con una nota di Guido Fink)”, Paragone, 428, octubre, págs. 6-9.

Clerici, L. y Falcetto, B. (eds.), Calvino \& l'editoria, Milán, Marcos y Marcos.

Crovetto, P. L.: (1996) "Il castello dei destini che si biforcano", ponencia leída el 30 de noviembre en el congreso "Italo Calvino: a writer for the next millennium" (versión mecanografiada proporcionada amablemente por el autor. Las actas del congreso serán editadas por el Ayuntamiento de San Remo, a cargo de Giorgio Bertone).

De CARLI, L.: (1997) Internet. Memoria e oblio, Turín, Bollati Boringhieri. Ferrero, E.: (1993) "Edizioni Calvino", en Clerici-Falcetto eds., págs. 177-189.

Ferretti, G. C.: (1998) "Ma c'è anche un Calvino nascosto. E più umano", Corriere della sera, 10 de enero.

FIORI, C.: (1998) "Così il mito di Calvino oscurò Pasolini", Corriere della sera, 6 de enero.

Frigessi (ed.), D.: (1988) Inchiesta sulle fate. Italo Calvino e la fiaba, Bérgamo, Lubrina.

Genot, G.: (1969) "Borges", Il Castoro, no 31-32, julio-agosto. 
Giovanardi, S.: (1998) "Pasolini-Calvino: zero a zero", L'Espresso, 19 de febrero.

Giovannetti, P.: (1993) “Calvino, la scuola, l'editoria scolastica: l'idillio dimezzato”, en Clerici-Falcetto eds., págs. 35-82.

Guglielmi, A.: (1998) “Ma Calvino ha vinto la sfida del '900”, Corriere della sera, 22 de enero.

LAFOn, M.: (1996) "Borges, Calvino et la littérature", en Sicard-Moreno eds., vol 1, págs. 11-25.

Landow, G. P.: Hypertext. The Convergende of contemporary Critical Theory and Thechnology, Baltimore, John Hopskins University Press (Ipertesto. Il futuro della scrittura, Boloña, Baskerville, 1993).

Mclaughlin, M. L.: "Borges e Calvino, la letteratura e l'intelletto", en Sicard-Moreno eds., págs. 85-103.

Merrell, F.: (1997) "The Writing of Forking Paths. Borges, Calvino and Postmodern Models of Writing”, Variaciones Borges, 3, págs. 56-68. Nava, G., 1996, "Calvino interprete di Borges", en Sicard-Moreno eds., págs. 67-77.

Paoli, R.: (1993) "Borges y Calvino", en Anthropos. Revista de documentación cientifica de la cultura, no 142-143, marzo-abril, págs. 151-157.

(1997) Borges e gli scrittori italiani, Nápoles, Liguori.

Patrizi, G.: (1993) “Dal testo opaco. Calvino prefatore”, en ClericiFalcetto eds., págs. 121-140.

POLACCO, M.: (1991) “'Se una notte d'inverno un viaggiatore: il testo e i suoi modelli”, Annali della Scuola Normale Superiore di Pisa. Classe di Lettere e Filosofia, s. 3, 21, págs. 995-1029.

Santos Unamuno, E.: (1995) "Poética de la totalidad y paradigma informático en Jorge Luis Borges e Italo Calvino", Culture. Annali dell'Istituto di Lingue della Facoltà di Scienze Politiche dell'Università degli Studi di Milano, No 9, págs. 47-88.

(1996) “Borges en Italia: perfil de una recepción”, Culture, No 10, págs. 155-189.

Sicard, A. y Moreno, F. (eds.): (1996) Borges, Calvino, la literatura, actas del congreso de Poitiers (31 de mayo-4 de junio de 1994), Madrid, Fundamentos.

TABUCCHI, A.: (1998) "I cambi di stagione della letteratura", Corriere della sera, 15 de enero.

Tamponi, M.: (1981) "Con gli strumenti dell'ironia" (Parliamo con Italo Calvino dei suoi libri, dell'impegrno' letterario, della Germania, del terrorismo), Avanti!', 85,39, 15-16 de febrero.

Tesio, G.: (1991) "Nota al testo", en Calvino, Italo, I libri degli altri. Lettere (1947-1981), edición de Giovanni Tesio, Turín, Einaudi, págs. IX-X.

VARSAVA, J.: (1990) “The Last Fictions: Calvino's Borgesian Odysseys”, en Aizenberg, Edna (ed.), Borges and His Successors. The Borgesian Impact on Literature and the Arts, Columbia/Londres, University of Missouri Press. VIAN, C.: (1980) Invito alla lettura di Jorge Luis Borges, Milán, Mursia. YurkiEvich, S.: (1996) "El cristal y la llama”, en Sicard-Moreno eds., págs. $27-40$. 